\title{
La narrativa fílmica de José Emilio Pacheco: el guion cinematográfico $E l$ castillo de la pureza
}

\section{The Filmic Narrative of José Emilio Pacheco: the Screenplay El castillo de la}

pureza

Resumen

El artículo propone una lectura crítica del guion cinematográfico El castillo de la pureza, del escritor José Emilio Pacheco, con el objetivo de insertar el texto en el marco de la obra narrativa del autor. Se examinan las analogías que presenta el guion con la descripción de la psicopatología del nazi en la novela Morirás lejos, y con el tema del despertar erótico del adolescente en El principio del placer y Las batallas en el desierto.

Palabras clave: José Emilio Pacheco, El castillo de la pureza, Morirás lejos, guion cinematográfico, cine y literatura.

Abstract

This article proposes a critical analisis of the screenplay El castillo de la pureza, by José Emilio Pacheco, in order to bring new light on the relationship between this text and the author's lite rary works. It will focus on the analogies between the screenplay 
and the description of the psichopatology of the nazi in the novel Morirás lejos, and the theme of erotic awake in the young characters of El principio del placer and Las batallas en el desierto.

Keywords: José Emilio Pacheco, The castle of purity, You will die in a distant land, Screenplay, Film and literature.

T a trayectoria como guionista del escritor mexicano José Emilio Pacheco comprende cuatro guiones filmados, todos por el director Arturo Ripstein: El castillo de la pureza (1972), Fox trot (1976), El santo oficio (1973) y El lugar sin limites (1977); a los que se añade un guion sin filmar, El obsceno pájaro de la noche (1977). Dos de estos guiones han sido publicados, El castillo de la pureza (1973) y El santo oficio (1980), y hay noticias de la existencia de otros guiones inéditos y sin filmar. ${ }^{1}$ El objetivo de este artículo es el de proponer una perspectiva crítica que incluya los textos fílmicos del autor en la trama de su obra como escritor, perspectiva de la que hay escasos intentos (vid., por ejemplo, Hind, 2004). Para ello, propondremos el análisis del guion El castillo de la pureza, texto que reconstruye en un relato de ficción el caso de Rafael Pérez Hernández, un hombre que encerró a su familia durante casi dos décadas en una casa en el norte de la ciudad de México a mediados del siglo pasado, y que fue arrestado en Julio de 1959, para después suicidarse en la cárcel de Lecumberri en 1972 (Morales, 2012: 2). Narrar la historia concentrando la atención en los días anteriores al descubrimiento del crimen por parte de la policía es el punto de partida de la reescritura ficcional del episodio realizada por $\mathrm{Pa}$ checo. En virtud de esta delimitación temporal, todo el tiempo anterior, desde la concepción del proyecto de encierro hasta sus dieciocho ańos de duración, constituye un antecedente implícito

${ }^{1}$ Vid. el artículo: "Denosta Arturo Ripstein cinta Mariana, Mariana" (2014). 
que puede ser reconstruido gracias a indicios y elementos significativos. De hecho, el relato es en gran medida, y especialmente en la parte inicial, la presentación de la casa y de los personajes que la habitan; la observación de la rutina, supuestamente inalterada en el tiempo, de la familia prisionera del padre, cuyo nombre en el film es Gabriel Lima. Simultáneamente, el guion presenta una progresión dramática basada en la crisis del protagonista y del control que ejerce sobre su familia, la cual se debe a varios factores convergentes que se van agudizando cada vez más y que provocan la creciente violencia en las reacciones del personaje. La estructura del film escrito El castillo de la pureza resulta, por lo tanto, de la combinación de estas dos líneas narrativas.

\section{Palabra e imagen en el guion cinematográfico: escribir para mostrar}

La presentación de la casa y de "lo aberrante cotidiano" de la familia, como lo define García Riera (1988: 95), consiste en un movimiento de exploración de los ambientes y espacios de la historia, cuidadosamente estructurado con la finalidad de enfatizar ciertos elementos clave. El texto va 'mostrando' la casa y los personajes en sus actividades durante un día cualquiera, con el fin de que la atención del lector-espectador se detenga en algunos detalles. Por supuesto, se trata de una 'visión' en sentido figurado, ya que el guion cinematográfico es un texto escrito que exige que el lector traduzca mentalmente el discurso verbal en un flujo de imágenes en movimiento. Como escribe Vito Galeota, en el guion "la figurazione del film, atto dell'immaginazione che accompagna la lettura del testo ed è da questa generata, fa parte della fiction letteraria, ed è all'origine di tutte le qualità formali di questo tipo di narrazioni”" (1993: 439). Por lo tanto, el guion incorpora estructuralmente la imagen en lo verbal, ya que, citando nuevamente a Galeota, en él 
"l'immagine audio-visiva entra come linguaggio iconico che, privo della sua fisicità, attiva una funzione integrativa dell'immagine letteraria" (1993: 439). El castillo de la pureza es un texto especialmente atento a que los aspectos fundamentales de la historia, sobre todo en la fase inicial del relato, queden enfatizados de manera fílmica, es decir, en base a estrategias discursivas aptas a ser traducidas mentalmente según una articulación cinematográfica.

Es posible advertir lo anterior ya desde las primeras líneas del texto, que describen un proceso de audiovisión expresamente cinematográfico, con un movimiento que va de los créditos sobre fondo negro, a la entrada de la banda sonora, hasta la puesta en foco de un plano en detalle: "Títulos sobre fondo negro. Sonido de agua al caer sobre la superficie metálica. Se aclara la imagen y aparecen en gran acercamiento gotas de agua que resbalan por un metal oxidado" (Pacheco, 1973: 11). La descripción continúa con un movimiento de cámara que permite una visión cada vez más completa del entorno, gracias a la progresiva ampliación del plano de encuadre, culminando en un plano de contextualización general:

La cámara retrocede para ver una serie de latas vacías unidas por un cordel. Llueve. En medio acercamiento vemos que la fila de latas cuelga de una puerta de madera. Se ha puesto para que nadie entre o salga sin ser advertido. La lluvia cae sobre el patio interior. Estamos en una casa ruinosa de la ciudad antigua que en otros tiempos fue un palacio (Pacheco, 1973: 11).

Como puede verse, la progresiva ampliación del encuadre coincide con breves explicaciones que orientan la comprensión del lector. Sin embargo, dichas indicaciones no siempre se mantienen, y más adelante el texto deja más bien que algunas imágenes hablen por sí mismas. En efecto, la exploración de la casa continúa, a través de un procedimiento de enumeración que debe percibir- 
se como un montaje de planos autónomos, culminando en una imagen de cierto impacto, cuya carga expresiva se comunica sin comentarios adicionales:

cortes sucesivos describen el patio: una fuente adosada a la pared, helechos y otras plantas de sombra que le dan un aspecto sobrenatural pero de alguna manera acogedor. Una viga apuntala el muro. Dispersas en el suelo, cubetas, una carretilla, una escalera de mano. Hay una pila de jaulas de pájaros llenas de ratas (Pacheco, 1973: 11).

Es importante subrayar la atenta articulación del discurso, que enfatiza la visión de la "pila de jaulas de pájaros llenas de ratas" gracias a su colocación al final de la descripción y a la presencia del verbo "hay" que encabeza la última frase, aislándola del resto de la enumeración anterior. Se entiende que estas imágenes se ofrecen como elementos especialmente relevantes del mundo de la historia y acaparan la atención del lector-espectador, llegando incluso a constituirse en símbolos de las obsesiones, manías y fobias del personaje protagonista, Gabriel Lima, como se verá más adelante. El corte siguiente, gracias al que "vemos por un instante el exterior grandioso y arruinado de la casa”, permite inferir claramente que la casa misma se concibe como "un personaje importantísimo" del film, según apuntaba García Riera (1988: 94), cuya identidad está determinada, por supuesto, por el uso y el sentido que le ha dado el protagonista al concretar su proyecto de encierro. Por lo tanto, las descripciones de los espacios, conforme la narración los va mostrando, tienen una importancia crucial en la economía del relato. El primero es el taller donde la familia fabrica un veneno raticida, cuya connotación principal está dada por la presencia de otras "jaulas llenas de ratas, apiladas unas sobre otras en un extremo del cuarto" (Pacheco, 1973: 12-13), pero también por el gran número de objetos de trabajo que saturan el espacio, y por el elemento 
auditivo que satura la banda sonora y complementa la atmósfera del lugar: "una máquina para calentar los materiales [...] produce un ruido intermitente" (12). El castigo que el padre le impone a la menor de las hijas (Voluntad) por haberse distraído durante el trabajo, motiva la descripción del que quizás sea el ambiente más anormal y angustiante de la casa, "un sótano húmedo perpetuamente en tinieblas" donde "Gabriel ha construido tres celdas de castigo" (12). Un detalle en especial sobresale en la descripción de la figura de Gabriel al encerrar a la niña en una de estas celdas: "un enorme manojo de llaves que suenan continuamente" y que aparece "colgado del cinturón" del protagonista (12-13). Al guardar las llaves de todas las puertas, se subraya el control que éste posee del espacio, e indirectamente el hecho de que toda la casa es el reflejo exacto de su concepción del mundo. Para el lector-espectador, entonces, todo se va configurando a través de la serie de elementos con valor simbólico que el texto dispone para su lectura 'audiovisual': las latas en la puerta, las jaulas con las ratas, el taller con su ruido intermitente, los sótanos con las celdas, el manojo de llaves.

$\mathrm{Si}$, por un lado, la dinámica narrativa de descubrimiento y observación de los ambientes de la casa sigue vigente hasta el final del relato, por otro, su función esencial puede considerarse realizada con la presentación de ciertos elementos clave que evocan algunas tensiones dramáticas relevantes en la historia. Se trata especialmente del elemento del erotismo, asociado al personaje de la madre, y del efecto del transcurrir temporal, que se encarna en la imagen de un objeto que se vislumbra al fondo del patio de la casa.

En la secuencia que introduce el primer elemento, la descripción retoma el mismo movimiento cinematográfico de las primeras líneas del guion, es decir, un plano detalle seguido por un alejamiento de cámara que sitúa la imagen en su contexto: "Llena la pantalla la boca de Beatriz que se pinta los labios. La cámara se aleja y vemos que Beatriz está sentada frente al tocador” (14). Es 
de notar que, colocándose esta secuencia en posición inmediatamente posterior a la de la nińa encerrada en el sótano oscuro, el montaje narrativo produce un sorprendente choque entre los dos ámbitos semánticos, erotismo y represión, e involucra también el problema del rol pasivo de la madre frente al cruel castigo de la hija. El efecto simbólico apunta, como decíamos, a la estructura misma del guion, en el sentido de que evoca una de sus tensiones principales, precisamente la que se da entre la fuerza del deseo erótico y la obsesión de Gabriel Lima por el control. Por el momento, la descripción va trazando la caracterización del personaje de Beatriz, la esposa del protagonista, subrayando su adscripción a lo erótico-femenino frente al rol de padre y patrón del marido. Muchos elementos de la secuencia lo confirman, pues tanto los objetos de la habitación como las acciones de la mujer se inscriben en este ámbito semántico: el cuarto de Beatriz está lleno de "floreros vacíos y velas [...] cientos de potes, frascos, pinzas, pintura de uñas" (14), y sus únicas acciones son pintarse los labios y limarse las uñas. De ello se deduce que la esposa también vive un encierro simbólico en su rol de objeto erótico, al margen del resto de la organización familiar dirigida por el padre. Sin embargo, la imagen de los labios que "llenan la pantalla", parece sugerir una tensión inscrita en la naturaleza misma de lo erótico, que tiende a desbordar cualquier intento de sujeción. Como se verá, se trata de una tensión que se manifiesta en el curso del relato de varias maneras, especialmente asociada al transcurso del tiempo, puesto que en la historia juega un papel crucial el despertar del deseo erótico como momento ineluctable del crecimiento de los dos hijos mayores, Utopía y Porvenir. A dicha asociación la antecede un sugerente elemento, el cual se hace visible en la descripción de la secuencia siguiente, que retoma la exploración de la casa a partir de una nueva enumeración de objetos presentes en el patio interior, culminando con una imagen de gran poder expresivo: "Hay una fuente seca 
adosada a la pared, vestigios de hiedra, macetas de pedacería, aros infantiles de hierro. Al fondo, en el zaguán, un Dodge modelo 1938 que alguna vez fue verde. Se nota claramente que no se ha movido en muchos años" (14). El coche inmovilizado no sólo reitera el tema del encierro, sino que funciona como indicio de la dimensión temporal del mismo, confirmando que la descripción de estas secuencias resume un largo antecedente, cuyo remoto origen la imagen evoca en cuanto vestigio de un tiempo anterior. Esta dimensión temporal es muy importante para comprender de manera plena la representación que el guion propone del proyecto del protagonista, ya que la caracteriza básicamente no sólo desde el punto de vista espacial (la clausura y la segregación del mundo exterior) sino también como intento por detener el paso del tiempo y sus consecuencias. Después de haber presentado estos elementos, que configuran algunas de las tensiones principales de la historia, se introduce en la secuencia siguiente el primer síntoma de crisis del protagonista, la señal de que estamos contemplando un mundo que se encuentra en la inminencia de su derrumbe. Gabriel Lima entra en su habitación personal, protegida, como la entrada de la casa, por un sistema de alarma formado por latas colgadas y cerrada con candado. A pesar de este sistema de control, en el protagonista se insinúa la sensación de que alguien ha tocado sus cosas, y ante la imposibilidad de comprobarlo sufre un ataque de angustia neurótica. El estado de ánimo del personaje, por supuesto, se hace visible en su actitud exterior y en su conducta gestual: "se detiene y golpea la puerta con la palma de la mano derecha. Los golpes van aumentando en intensidad". Un procedimiento de montaje crea un contrapunto con el silencio que sobreviene cuando cesan los golpes y llena de manera siniestra todo el espacio de la casa: "el sonido de las palmas cesa de pronto. Sólo se oye el rumor de la lluvia. La cámara abarca el patio y la cocina” (Pacheco, 1973: 17). 
De esta forma, el lector-espectador se da cuenta de que la extraña rutina de esta familia encerrada está entrando en una fase crítica cuyos resultados son imprevisibles.

\section{La construcción dramática del guion}

Aunque se trate, como hemos dicho, de hechos tomados de la realidad, la reconstrucción de los mismos en un relato fílmico depende de las operaciones creativas de los autores, responsables de seleccionar, reordenar, suprimir o ańadir elementos a partir de los acontecimientos en los que se inspiran, y que son reconfigurados en una construcción dramática determinada. En El castillo de la pureza, esta se va desarrollando alrededor de la permanente tensión entre el espacio cerrado de la casa, concebido como un microcosmos autónomo, y el mundo exterior, al que sólo el protagonista accede y que los hijos no han visto nunca. Por supuesto, la contradicción entre el proyecto del protagonista, su insana utopía de perfección familiar, y todos los factores, pulsiones y fuerzas que se oponen a su realización, suscitan la expectativa de una posible liberación de la familia de su encierro. Tales factores dependen, en algunos casos, de la actitud y la conducta de los hijos, que no siempre corresponde a la que el padre se espera de ellos; otros se gestan en la relación de Gabriel Lima con su mujer, que también presenta varios elementos de contradicción, y, por último, se deben a la intrusión del mundo externo. En este contexto, la clave de la construcción dramática es la reacción cada vez más agresiva y violenta del protagonista frente a la presión de estos factores. De esta forma se plantea no sólo la tensión entre el encierro y la liberación de los personajes, sino se introduce una nueva posible resolución, basada en la amenaza de exterminio de la familia por parte del padre. 
En efecto, tras la primera señal de crisis del protagonista, el relato va presentando otras cada vez más agudas, en una línea de tensión ascendente contrapunteada por algunos momentos de engañosa distensión. En una secuencia destinada a mostrar el tipo de educación que Gabriel Lima le proporciona a sus hijos - leyéndoles citas famosas que, desde su punto de vista, confirman la bondad del estilo de vida que les ha impuesto-, el lector-espectador asiste al primer momento de lo que se irá configurando como conflicto entre padre e hijo mayor: "Porvenir no oculta su aburrimiento por las clases del padre, y acepta el castigo en las celdas del sótano sin inmutarse" (Pacheco, 1973: 31-33). Como hemos dicho, la intensificación dramática se desarrolla por medio de varias situaciones tensas, como la tortuosa relación del protagonista con su esposa Beatriz, en la que se muestra la perturbación que lo afecta frente a lo femenino y la agresividad con que reacciona a los celos que lo atormentan. Cuando amenaza a su mujer con una navaja, vemos la primera señal de la pulsión asesina del personaje (59-61). Otro elemento de tensión es la angustia del protagonista por los problemas económicos, que lo llevan a obsesionarse con la idea de que se morirán de hambre, como en una suerte de síndrome de estado de sitio (56). Por supuesto, los diversos motivos de tensión interactúan produciendo un efecto de acumulación en el estado de ánimo de todos los personajes; especialmente de Gabriel Lima, con manifestaciones cada vez más directas de su impulso homicida, que estalla de manera definitiva en su actitud contra los hijos. Primero contra Utopía, por el hecho en sí mismo de descubrir que ya es una mujer (73). Luego, contra Voluntad, por su instinto de lanzarse a la calle al ver abierta la puerta de la casa (80-83). Pero, sobre todo, en el que puede considerarse el clímax dramático del relato: el incesto entre los dos hijos mayores, Utopía y Porvenir, del que ya se habían visto indicios. Gabriel los descubre en la noche, en el interior del Dodge abandonado en el patio, y su reacción es 
casi incontrolable: primero golpea a Porvenir y lo arrastra hasta la celda, luego azota a Utopía con un cinturón y la encierra también. Llega incluso a darle un puñetazo a Beatriz, quien intenta proteger a los hijos, y finalmente concluye acusándola nuevamente por el sólo hecho de ser mujer: "Todo es por tu culpa. Tú tienes la culpa. Mira lo que has hecho..." (87-91). A partir de este momento, el clima en la casa será aún más parecido al de una suerte de angustioso campo de concentración, donde los hijos viven permanentemente vigilados, obligados a trabajar y bajo la constante amenaza de muerte del padre, quien a menudo grita en las noches acusando a la esposa y amenazando con matarlos a todos.

En estas circunstancias, todos los miembros de la familia se rebelan de alguna forma: Utopía lo hace de manera indirecta, escribiendo un mensaje para pedir ayuda, en el que cuenta que su padre los tiene encerrados desde que nacieron y que ahora los quiere matar (101); Beatriz, por su parte, ante una nueva provocación de Gabriel, le responde por fin con disgusto, suscitando en él una inesperada reacción de preocupación y postración (102-104); Porvenir, finalmente, opone resistencia a una nueva agresión física de su padre, quien reacciona con gran asombro y nuevas amenazas (107). Así se prepara la resolución de la historia, al plantear nuevamente los diversos desenlaces posibles: la liberación de la familia, un nuevo equilibrio en el encierro o la masacre familiar. Además, al disponer una serie de equivocaciones y coincidencias, también se prepara una acción final convulsa e imprevista. El elemento principal para este efecto es la convicción de Utopía de haber llamado a la policía, aunque su mensaje, lanzado desde la azotea de la casa, en realidad se ha perdido en un una coladera arrastrado por la lluvia (109-110). Dicha convicción parece confirmarse cuando un inspector de la policía acompaña a Gabriel a la casa, aunque en realidad sin saber nada de la situación familiar, sino sólo para investigar la fabricación del raticida. Por tanto, al verlo entrar, Bea- 
triz y Utopía actúan de manera rápida e inesperada, tanto para el policía como para el mismo Gabriel: Utopía al gritar desde su cuarto y Beatriz al disculparse con el inspector por haber encerrado a los hijos. La acción se desarrolla de manera confusa, pero al mismo tiempo coherente con la tensión que se ha ido profundizando hasta el momento, y que llega aquí a un punto de ruptura irreversible: el impulso de la familia por liberarse, que ahora se manifiesta plenamente, frente al impulso de Gabriel por destruirla. En efecto, al principio el inspector permanece atónito sin entender lo que está ocurriendo, lo que le da el tiempo a Gabriel de amenazar a Porvenir con un cuchillo y arrastrar al resto de la familia a la sala, dispuesto a matarlos a todos (119-122). La acción es muy repentina, pero termina por mostrar la inconsistencia de Gabriel y de sus amenazas, ya que Beatriz y Porvenir lo neutralizan fácilmente, y la policía lo detiene. De hecho, este aspecto prepara la paradoja final del relato, ya que al caer Gabriel en manos de la policía, mujer e hijos tratan de defenderlo. De esta manera, se insiste en que el condicionamiento de la familia es irrecuperable, configurándose como un estado permanente de encierro y dependencia del padre, aun en su ausencia. Esto se expresa claramente en las secuencias finales, en las que no sólo vemos la imagen de Gabriel tras las rejas, sino también la de Beatriz y sus hijos encerrándose nuevamente en la casa sin saber qué hacer, de regreso de la comisaría donde está detenido el padre (126). Incluso se enfatiza más lo anterior con la última imagen del film, que al repetir la de abertura evoca cierta circularidad de la historia: vemos las latas atadas a la puerta, moviéndose con suavidad a causa del viento y la lluvia. La imagen guarda un evidente significado simbólico: a pesar de la detención del padre, el encierro sigue allí y la familia nunca podrá realmente salir de la casa. 


\section{El mundo narrativo de Pacheco y El castillo de la pureza}

Pasaremos ahora a analizar el guion El castillo de la pureza focalizando aquellos aspectos del texto que reflejan la poética y las visiones del mundo y de la narración de su autor. Para este efecto, nos parece interesante comenzar con el análisis del carácter que adquiere el proyecto utópico de Gabriel Lima en el relato.

Como hemos visto, en las primeras secuencias encontramos indicios importantes de la personalidad del protagonista y de su visión del mundo, como la presencia de las latas en las puertas, las celdas en los sótanos, el gran manojo de llaves que lleva siempre consigo. Todo apunta a una obsesión paranoica del personaje por el control, la vigilancia y el castigo; la mera sensación de que algo pueda escapar a este control provoca en él una aguda sensación de crisis y sufrimiento. En estos elementos encontramos una pista que nos conduce a una de las obras más importantes de Pacheco: la novela Morirás lejos. En efecto, también en este texto, desde las primeras páginas, el lector se percata de que el acto de vigilar y la imaginación paranoica de un hombre encerrado constituyen el principio de la vertiginosa aventura narrativa. Así lo indica su célebre incipit, en el que se presenta a un hombre vigilando a otro:

Con los dedos anular e índice entreabre la persiana metálica: en el parque donde hay un pozo cubierto por una torre de mampostería, el mismo hombre de ayer está sentado en la misma banca leyendo la misma sección: anuncios clasificados del mismo periódico: El Universal (Pacheco, 1967: 9).

Poco más adelante se insinúan las dudas del personaje que mira y se describe su carácter paranoico, asociado a un encierro:

Es posible, no obstante, que eme trate de resolver un problema mucho más inmediato: el hombre sentado en la banca del parque 
¿Es un perseguidor? En el caso contrario pueden formularse cargos que si bien absolverían a eme de un pasado que por desgracia no es ilusorio, acaso lo señalaran como sujeto-objeto de una paranoia cuyos síntomas exacerba el encierro (1967: 10).

El nombre del personaje que se encuentra encerrado y que observa desde su casa a otro hombre sentado que está leyendo los anuncios del periódico es eme. A partir de esta situación inicial, comienza una narración que es en gran medida un torbellino de conjeturas sobre la posible identidad de este hombre sentado, denominado Alguien. Como aclara el párrafo citado arriba, estas conjeturas guardan cierta relación con la imaginación paranoica de eme, la cual es exacerbada además por su situación de encierro, lo que le provoca temer que el hombre pueda ser un perseguidor.

Llama la atención la primera acción descrita por la novela (el gesto de entreabrir la persiana metálica con los dedos anular e índice para mirar a través de ella) que plantea la mirada como principio mismo de la narración, con una clara invitación al lector a visualizar la escena, fílmicamente, desde la perspectiva ocular del personaje. Como apunta Negrín, "la estructuración de la novela está definida por el juego de miradas" (2013: 426), lo que sin duda representa un punto de contacto con el lenguaje audio-visual. Enseguida cobra también relevancia la descripción de la casa donde eme se encuentra encerrado, lo cual confirma que la situación inicial de clausura o encierro y temor paranoico del espacio exterior eran elementos que ya estaban presentes en el imaginario creativo de José Emilio Pacheco al redactar el guion de El castillo de la pureza. Otros indicios de la afinidad creativa entre Morirás lejos y El castillo de la pureza se encuentran en algunos detalles relacionados con los personajes. Por ejemplo, en el guion, como vimos arriba, la imagen de las jaulas llenas de ratas aparece súbitamente, causando sorpresa y extrańeza, con la función de anticipar la obsesión del personaje por estos animales; en la novela, al final del primer 
apartado, encontramos la descripción de una obsesión semejante de eme por los gusanos:

aquellos gusanos torturables que los nińos llaman azotadores y que eme, nostálgico, primero vivisecciona con una hojita de afeitar y luego aplasta*, o bien arroja al bóiler donde, corruscantes, evocan -a punto de precipitarse por la rejilla, entre la ceniza aun moteada de fuego- la imaginería católica del infierno.

*lo cual provoca la secreción de un líquido amarillo purulento (Pacheco, 1967: 13).

Esto puede relacionarse también con la presencia de ciertos tics neuróticos de los personajes, tanto en la novela como en el guion. Como vimos, el gesto de Gabriel Lima de golpear insistentemente la puerta de su habitación, o la palma de su mano, funcionan como síntomas de su desequilibrio mental, sobre todo a partir de la sensación de perder el control de las cosas; en la novela, el gesto más significativo en este sentido quizás sea el de eme al trazar una suerte de "signos prefenicios o anteriores a la escritura [...] con la uña del indice izquierdo en la pared de yeso contigua a la ventana" (1967: 60: las cursivas son mías), lo que también remite a la caracterización psico-patológica del personaje (Cluff, 1979: 27). Si a partir de estos primeros elementos aceptamos que existe una analogía profunda entre las dos obras, entonces podríamos suponer que la representación del proyecto familiar de Gabriel Lima en El castillo de la pureza tiene un significado que no se limita a la curiosidad suscitada por un caso de nota roja metropolitana, sino que refleja los temas de la novela Morirás lejos, cuyo valor ético, histórico y político es explícito y trascendente, como observa Rafael Olea: "En Morirás lejos, Pacheco [...] proyecta su literatura a una dimensión superior, de profundo contenido ético" (2010: 492). En otros términos, podríamos avanzar sobre la hipótesis que, al redactar un guion sobre el caso real de Rafael Pérez Hernández, 
Pacheco decide conferirle a los hechos una caracterización cercana al mundo narrativo de su novela anterior, resultando por lo tanto la utopía de Gabriel Lima una suerte de metáfora de un sistema totalitario a escala familiar.

Para profundizar en esta hipótesis es preciso detenerse en la expresión del pensamiento del protagonista sobre su propio proyecto, que en el guion se da a través de algunos diálogos cruciales entre éste y su esposa Beatriz. En este sentido, una de las secuencias más significativas ocurre cuando, al entrar en la habitación de la esposa, Gabriel hace una siniestra pregunta completamente fuera de contexto: “¿Te imaginas cuántos muertos cabrían apilados en este cuarto?", mientras "mide con los ojos el espacio de la habitación” (Pacheco, 1973 :39). La lúgubre imagen no deja de evocar escenarios reales de masacres y exterminios, como es el caso de los campos de concentración nazis cuya descripción ocupa buena parte de la novela Morirás lejos. Luego continúa: “Tengo asco. Hay millones de ratas por todas partes. Ya no se mueren. Hay que hacer raticidas más potentes. [...] Las bestias sólo buscan el placer. Y reproduciéndose perpetúan su horror y su asquerosidad" (39). Como puede verse, el discurso del protagonista delata la obsesión paranoica que lo impulsa a una suerte de guerra contra las ratas. Más adelante, en otra secuencia, Gabriel le dicta a su esposa una carta dirigida al "seńor Ministro", en la que explica la necesidad de exterminar a dichos animales con urgencia y sin piedad: "Las ratas son enemigas del género humano [...] Entonces deben ser totalmente aniquiladas por el más fuerte [...] No debe haber piedad" (67). De esta manera, el personaje queda caracterizado por la idea enfermiza de tener una misión fundamental: liberar al mundo de unos seres asquerosos que, desde su punto de vista, constituyen el principal agente de corrupción de la sociedad. El razonamiento de Lima no termina aquí, pues en el diálogo anterior con Beatriz 
hay un pasaje sumamente importante, que explica la decisión del encierro:

La bestias sólo buscan el placer. Y reproduciéndose perpetúan su horror y su asquerosidad [...] Y con la gente es lo mismo. Por las ratas he aprendido a conocer a los hombres. Son iguales. Por eso no quiero que ustedes tengan ningún contacto con el mundo. [...] Tú conociste el mundo. Tú sabes lo que es; yo lo veo cuando salgo... La decisión fue buena. La prueba está en que los niños son sanos, puros y felices. En cambio, si estuvieran en el mundo ya se habrían corrompido (39-41).

Para Lima existe una asociación inmediata entre ratas y hombres, por eso decidió aislar a su familia, para preservarla en una suerte de pureza originaria. Cabe observar que en esta forma de pensar actúa una pulsión agresiva y mortífera que también se manifiesta como instinto reprimido contra los seres humanos, y que se desahoga sólo de forma imaginaria, a través, por ejemplo, de la imagen de los muertos apilados en la habitación de su esposa. De esto también se puede inferir el hecho de sentirse un ser extraordinario aunque incomprendido, incluso pre-destinado, que se reconoce incluso en las predicciones del profeta Nostradamus: "Gabriel se muestra satisfecho porque supone que las profecías se refieren a él y que todo coincide" (65). De esta forma, José Emilio Pacheco estaría configurando la parodia de un sistema totalitario a nivel familiar, en el que Gabriel Lima es amo supremo y guía, que dirige y controla la vida de su esposa y de sus hijos en todos los detalles, plasmando incluso sus conciencias y forma de ser. No sorprende esta posible lectura si recordamos que en Morirás lejos el autor realiza un minucioso análisis de la fenomenología del nazismo y de la psicopatología del nazista, haciendo énfasis en la persecución del pueblo judío y en el proyecto de exterminio de éste y de toda raza considerada inferior. Las resonancias de este discurso 
son patentes en el guion, sobre todo las que provienen de la segunda sección de la novela, dedicada a la descripción del ghetto de Varsovia y al relato de su destrucción, donde se establece desde el comienzo el principio fundamental en el que se sustenta la acción de someter y exterminar a los judíos emprendida por la Alemania nazista: "El fin perseguido al instituir el ghetto de Varsovia es acabar con los judíos como se exterminó a los perros de Constantinopla” (Pacheco, 1967: 40; las cursivas son mías). Apunta Dorra que la referencia a los perros no debe entenderse como una metáfora, sino precisamente como el mecanismo clave de la deshumanización del otro que ejerce el nazismo (1986: 190). Más adelante, la narración recuerda que el gueto era atravesado por autobuses que lo visitaban como si se tratara de un zoológico, imagen que suscita la siguiente explicación:

Goebbels les ha enseñado qué significa el poderío y cómo hay que despreciar a las gentes de razas extrańas. Todo el misterioso poder que convierte a un hombre en asesino consiste en una transformación del mismo orden. En el alma humana se produce un mínimo reajuste de conceptos y sentimientos, pues hay que despojar a la futura víctima de todos los atributos de la humanidad para conferirle los de una especie repulsiva: una chinche, una rata o un piojo (Pacheco, 1967: 41; las cursivas son mías).

Imaginar a los hombres en general como ratas es precisamente el mecanismo que funciona en la mente de Gabriel Lima en El castillo de la pureza; también, explica la importancia, en este texto, de la presencia de estos animales como imagen símbolo. Este procedimiento de "inversión de lo humano", "animalización" o "deshumanización", es "recurrente en la narrativa de José Emilio Pacheco” (Jiménez de Báez, 1979: 235). En Morirás lejos, abundan las menciones a ratas u otros "animales repulsivos", que confirman dicho mecanismo, sobre todo en relación con la descripción del 
personaje de eme, cuya identidad, recordemos, a partir de la sección titulada "Totenbuch", está asociada a una serie de hipótesis relacionadas con alguna figura o función del partido NacionalSocialista Alemán. En un pasaje de la sección "Salónica" referida al presente de eme, se afirma que:

Aunque parezca extraño o monstruoso, palabras tan vulgares, tan poco imaginativas refiriéndose a eme, la única forma de mitigar sus dolencias es oler ciertos raticidas, ciertos insecticidas cuyo acre aroma se asemeja, a juicio de los expertos, al que tuvo el gas de las cámaras.

Los roedores que constantemente llegan hasta el cuarto de eme prófugos de las demoliciones que se suceden en los alrededores -, las moscas y mosquitos nacidos en los consiguientes muladares no lo dejan en paz y le horroriza pensar en la basura que cubre el sitio antes ocupado por viejas casas.

Desde hace tiempo eme pasa las horas al acecho. En el alba lo despierta el ruido de la trampa. Se levanta, enciende la luz, alcanza a ver las convulsiones de su enemigo con el esqueleto partido por la ratonera (Pacheco, 1967: 82; las cursivas son mías).

Son varios los aspectos interesantes que pueden subrayarse en el párrafo citado. En primer lugar, la semejanza entre el olor del raticida y el del gas de las cámaras de exterminio de los judíos. En segundo lugar, la caracterización de eme como individuo obsesionado y horrorizado por roedores y otros animales repulsivos. En tercer lugar, la imagen de la rata en la trampa percibida como enemigo. Todos ellos tienden un puente entre la novela y El castillo de la pureza, de manera que ciertos elementos del guion adquieren, a la luz de la lectura de Morirás lejos, una significación más precisa como evocaciones de mecanismos propios de la fenomenología y psicopatología del nazi. 
Por supuesto, al comparar estos aspectos es necesario plantear el problema de la interpretación del encierro al que Gabriel Lima somete a su familia; es decir: ¡se trata de una situación semejante a la de los campos de concentración, según una analogía entre Lima y eme que reproduce la significación del espacio propia de la novela, basada en el cerco, la reclusión, como forma de persecución y exterminio de los judíos? (Jiménez de Báez, 1979: 189, $201,202,208)$. En este sentido, como ya se notó anteriormente, es posible reconocer referencias al universo de los campos de concentración en la clausura impuesta por el padre a sus hijos. Es cierto que hay una diferencia fundamental, ya que en la visión de Lima el encierro sirve para proteger a su progenie de la corrupción del mundo y mantenerla en la pureza, y no para exterminarlos. Sin embargo, como ya se ha visto, la pulsión al exterminio es un factor subyacente a la desatinada utopía del protagonista, de la que van apareciendo seńales cada vez más explícitas conforme avanza la acción del guion. En otras palabras, el hombre que considera a todos los hombres como ratas termina por considerar de la misma forma también a sus hijos, y concibe, por lo tanto, la necesidad de eliminarlos, como desearía eliminar a todo ser inferior a él para lograr un mundo de pureza. De esta manera, en el guion se expresa la misma "sentencia de muerte", que según Rangel define la escritura de la novela (2013: 449), y el proyecto del protagonista de El castillo de la pureza se amolda a las características de la ideología nazi allí representada, salvando por supuesto las diferencias y recordando que en el guion el personaje es incapaz de cumplir sus amenazas, a pesar de sus ataques de violencia y de sus instintos mortíferos. 


\section{La perspectiva de los hijos: adolescencia y sexualidad}

Hay un aspecto importante del guion El castillo de la pureza que no está relacionado con la novela Morirás lejos, sino con otras obras significativas de la narrativa del autor, en especial El principio del placer y Las batallas en el desierto. Se trata de un motivo "especialmente recurrente" en la producción en prosa de Pacheco: "la nostalgia por la nińez, propuesta como estado de inocencia e ingenuidad que devienen pureza" (Trejo Fuentes, 1994: 214). En estas dos obras, los protagonistas son preadolescentes que se están alejando del mundo infantil y cuyo principal cambio es el deseo por una mujer. Como observa Benmiloud, a propósito de Las batallas en el desierto, "Este encuentro [con la mujer deseada] le permite a Carlitos pasar a la edad adolescente (o adulta, tal vez) y dejar atrás los juguetes, sinónimos de infancia” (2006: 315), o bien, como apunta Castro sobre El principio del placer: "Jorge pasa por la dolorosa experiencia del tránsito de una edad a otra”, cuya primera señal es "el surgimiento de la atracción [...] de su conciencia del deseo" (2014: 46). Lo esencial, para nuestro objeto, es que en ambos textos la dinámica narrativa está basada enteramente en la manifestación de este deseo y en el choque que provoca con una norma social que lo condena. Es a partir de este punto que se establece el vínculo con la dinámica de la acción narrativa del guion El castillo de la pureza, donde el objetivo principal del padre es mantener a los hijos en un estado de pureza que corresponde a una prolongación indefinida de la infancia, exorcizando su desarrollo sexual. El guion se insiste claramente en este aspecto al mostrar cómo los muchachos, sobre todo los dos mayores, que ya son físicamente adultos, se entretienen todavía con juegos infantiles. Por supuesto, dichos juegos reflejan la extrañeza de la situación en que han crecido los personajes: por ejemplo, al jugar los tres hijos y la madre a la "gallina ciega" y a las "estatuas de marfil" los per- 
sonajes "no corren, pero el juego tiene una indefinible ferocidad" (Pacheco, 1973: 17). Luego, en otra secuencia, el juego es más inquietante, ya que se trata de la simulación de un juicio contra "el coco", es decir un "costal vagamente antropomorfo" que "ha hecho muchas cosas feas" y cuyo castigo evoca una verdadera ejecución (48). Sin embargo, como ya hemos visto, el momento culminante de la crisis del proyecto del padre consiste en la revelación del incesto entre sus hijos mayores, Porvenir y Utopía, es decir, el momento en que el deseo erótico de los muchachos se muestra con toda claridad. Más allá de la naturaleza incestuosa del deseo entre los hermanos, es el erotismo en sí mismo lo que Gabriel Lima quisiera reprimir, por ser el aspecto que asimila los hombres a las ratas: "Es el instinto. Las bestias solo buscan el placer. [...] Y con la gente es lo mismo" (39), según una filosofía muy parecida a la que expresa el maestro de escuela del protagonista de El principio del placer: "La sexualidad es una maldición que mandó Dios contra el género humano" (Pacheco, 2010: 199). De esta forma, el tema del despertar del deseo y del abandono de la edad infantil, fundamentales en algunas de las obras narrativas más celebradas de José Emilio Pacheco, se vuelve a tratar en el guion El castillo de la pureza, donde desempeña una función crucial en la evolución dramática del relato.

Cabe recordar también que este tema conlleva otro más amplio y general, que atańe al sentimiento del cambio y del paso del tiempo. Esta asociación está magistralmente simbolizada por la presencia del Dodge abandonado en el patio de la casa: vestigio de una época anterior al encierro que ha quedado como cristalizado en su movimiento detenido. Esto se confirma cuando los muchachos buscan en él el espacio vital que les está vedado en la casa; por eso, el efecto del tiempo sobre sus cuerpos, el despertar erótico, queda asociado a la potencialidad de movimiento del vehículo. La obsesión por detener el tiempo en un instante de perfección se expresa 
también por medio de una nota de prensa que cuenta el caso de una pareja de jóvenes franceses que se suicidan porque "Eran tan felices que no encontraron otro modo de preservar su dicha” (94). Un tema del que hay señales innumerables en la producción literaria de Pacheco, que establece un vínculo no sólo con su narrativa, sino también con su obra poética, en la cual, como escribe Debicki, el tema del fluir del tiempo y de la imposibilidad de detenerlo es uno de los ejes fundamentales (1994: 62, 80).

\section{Bibliografía.}

Benmiloud, Karim, 2006, "El personaje de Mariana en Las batallas en el desierto: un retrato Pop Art”, en José Emilio Pacheco: perspectivas criticas, Pol Popovic Karic y Fidel Chávez Pérez (eds.), Siglo XXI, México, pp. 302-328.

Castro Rocha, Rogelio, 2014, Pasaje al desencanto, acercamiento critico a dos relatos de José Emilio Pacheco, Universidad de Guanajuato, Guanajuato.

Cluff Russell, Martin, 1979, “Morirás lejos: mosaico intemporal de la crueldad humana”, Chasqui, núm. 2, vol. 8, febrero, pp. 19-36.

Debicki, Andrew P., 1994, "Perspectiva, distanciamiento y el tema del tiempo: la obra lírica de José Emilio Pacheco", en La Hoguera y el viento, José Emilio Pacheco ante la crítica, Hugo J. Verani, Era, México, pp. 62-80.

Dorra, Raúl, 1986, La literatura puesta en juego, UNAM, México.

Galeota, Vito, 1993, "El gallo de Oro di Juan Rulfo e il genere letterario", en El Girador, Giovanni Battista De Cesare y Silvana Serafin (eds.), Bulzoni, Roma, pp. 436-448. 
García Riera, Emilio, 1988, Arturo Ripstein habla de su cine con Emilio García Riera, Universidad de Guadalajara, Guadalajara.

Hind, Emily, 2004, “Three Short Stories, Two Films, and One Crazy Commitment: José Emilio Pacheco”, La Torre, núm. 33, vol. 9, pp. 381-389.

Jiménez de Báez, Yvette, Diana Morán Garay Edith Negrín, 1979, Ficción e historia: la narrativa de José Emilio Pacheco, Colegio de México, México.

Morales, Fernando, Oscar Badillo y Karla Arreguín, 2012-2013, "Crimen y ficción: El caso de Macetones, La carcajada del gato de Luis Spota y El castillo de la pureza de Arturo Ripstein”, Cuadernos de Fronteras de Tinta, núm. 2, año 1, diciembre-marzo, disponible en: http://fronterasdetinta.acatlan.unam.mx/wpcontent/uploads/2013/05/Crimen_y_ficcion.pdf (consultado: 16/II/2016).

Negrín, Edith, 2013, "Señales cinematográficas en Morirás lejos: Fritz Lang en cuestión”, en Pasión por la palabra: homenaje a José Emilio Pacheco, Edith Negrín y Álvaro Ruiz Abreu (eds.), UNAM / UAM, México, pp. 423-438.

Olea Franco, Rafael, 2010, "La narrativa de Pacheco: una secreta y modesta complejidad", en Doscientos años de narrativa Mexicana, Rafael Olea Franco (ed.), Colegio de México, México, pp. 469-504.

Pacheco, José Emilio, 1967, Morirás lejos, Joaquín Mortiz, México. , 1973, El castillo de la pureza, Novaro, México.

, 1980, El santo oficio, Universidad Autónoma de Sinaloa, Culiacán.

2010, El principio del placer y otros cuentos, Tusquets, Barcelona.

Rangel, Asunción, 2013, "Escritura y sentencia de muerte: Morirás lejos de José Emilio Pacheco", en Pasión por la palabra: ho- 
menaje a José Emilio Pacheco, Edith Negrín y Álvaro Ruiz Abreu (eds.), UNAM / UAM, México, pp. 439-472.

S/f, 2014, "Denosta Arturo Ripstein cinta Mariana, Mariana", Excelsior, 29 de enero, disponible en: http://www.excelsior. com.mx/expresiones/2014/01/29/940880 (consultado: 16/ II/2016).

Trejo Fuentes, Ignacio, 1994, "La narrativa de José Emilio Pacheco: nostalgia por la infancia y ciudad gozable", en La Hoguera y el viento, José Emilio Pacheco ante la crítica, Hugo J. Verani, Era, México, pp. 214-220.

Recibido: 24 de febrero de 2016 Aceptado: 7 de junio de 2016 